\title{
AgricultureIsLife or how to facilitate innovation in agriculture through multi-disciplinary research?
}

\author{
Arnaud Monty, Sarah Garré, Jérôme Bindelle, Grégory Mahy, Magali Deleu, \\ Bernard Bodson, Éric Haubruge
}

University of Liège - Gembloux Agro-Bio Tech. TERRA. AgricultureIsLife. Passage des Déportés, 2. BE-5030 Gembloux (Belgium). E-mail: arnaud.monty@ulg.ac.be

Over the past decades, human use of environmental resources has largely increased and thereby led to ecological and socio-economic concerns. Damage to land and water ecosystems, resource depletion, and local extinction of formerly common species are welldocumented (Vitousek et al., 1997; Dirzo et al., 2003; Storkey et al., 2012). They highlight how unsustainable many human-environmental interactions are over the long term (Stern et al., 1996; Costanza et al., 1997; Costantini et al., 2008). Many of these interactions are linked to the processes by which human populations modify ecosystems to produce food, fiber, and fuel from plants and animals, in other words, agriculture in its largest sense (Tilman et al., 2002; van Grinsven et al., 2015). Therefore, agricultural research certainly has a critical role to play in facing these issues.

Intensive agriculture is based on maintaining agro-ecosystems in a uniform, regularly disturbed, and nutrient rich state (van Zanden, 1991; Tilman, 1999). Present-day agricultural practices often consist of raising animals and crops with appropriate genetics, managing soil fertility via chemical fertilizers, and controlling pests and weeds via chemical pesticides (Tilman, 1999). Crop rotation practices and tillage are also used to control diseases, pests and weeds (Curl, 1963; Ball, 1992). The adoption of these agricultural practices has led to major achievements in terms of productivity over the past decades (Conway et al., 1999), which was of great importance in order to feed an ever growing human population. However, that did not allow agriculture to achieve the goals that it should meet in the long term (Tilman et al., 2002), such as supplying mankind with a range of products and services in a way (i) that is cost-effective for the farmer; (ii) that does not lead to negative environmental effects, such as soil erosion, groundwater pollution, or river eutrophication; (iii) that is safe for the health of producers and consumers; and (iv) that is acceptable for all stakeholders, including the taxpayers who contribute to financing agricultural policies. The dependence of farmers on industrial inputs and agribusiness has reduced their autonomy and increased their production costs, and the adoption of simplified production systems has impoverished their knowledge about more self-sustaining practices (e.g., Marie, 2007; Fernández-Giménez et al., 2012). In addition, societal awareness about the intrinsic value of biodiversity and the considerable importance of ecosystem services has increased the demand by citizens for a more ecofriendly and more resilient agriculture (e.g., Halkier, 1999; Lin, 2011). This involves changes in production methods but also in patterns of consumption. It also raises the question of how to produce more value, using less resources.

Western Europe, with its long history of agricultural research, should have the potential for development of innovative solutions to this challenge. During the past decades, scientific and technical innovations have yielded major increases in crop and animal productivity. Nevertheless, current agricultural issues are more complex than increasing or maintaining yields (van Grinsven et al., 2015). This observation is in contrast to the present situation faced by smallholders in developing countries (Sayer et al., 2013), and what has been the focus of innovation during the green revolution (Evenson et al., 2003). While, in these countries, improving yields without dismantling rural societies is still a major concern to secure food sovereignty, today, in Western Europe, innovations must follow a different path to bridge the gap between food production, economy, environment, social viability, and cultural aspects. Even though the urgent needs are not the same in different parts of the world, the integration of these aspects is of great importance everywhere. Such a challenge demands a multi- and even inter-disciplinary strategy at the core of further innovation in agriculture. Encouraging collaborative research between scientific domains is probably only a first step in the long-term transformation of agriculture, but it might deliver the required breakthrough for another way of thinking on agriculture and its evolution/revolution. A whole range of actors, such as farmers, national and international 
agricultural research organizations, non-governmental organizations, media, entrepreneurs, and academia, involved in agricultural innovation must join efforts to develop more sustainable production systems through a diversity of innovative approaches (Hall, 2007). In this respect, the leading role that academia can play is being increasingly recognized in our knowledge-based society (Etzkowitz, 2003), notably in exploring new ideas through experimental and modeling approaches. Universities have traditionally been considered support structures for innovation by providing trained personnel, research results, and knowledge to society, which is why they have an important role to play in the triangle partnership between academia, governmental and non-governmental actors, including farmers' associations, and private companies (Leydesdorff et al., 1998). In collaboration with companies and government agencies, universities can take a proactive attitude and develop research activities that can generate innovative applications in the future. Examples such as the "Future Farms 2050" in Western Australia (Perring et al., 2012) illustrate how university-driven multi-disciplinary research can fuel agricultural innovation.

In 2013, Gembloux Agro-Bio Tech (University of Liège) launched AgricultureIsLife, a multi-disciplinary research platform aimed at exploring a range of innovations to improve the sustainability of agriculture in temperate Western Europe (www.agricultureislife. be). Next to the development of a modern research farm with 107 ha of experimental fields and pastures, the core of the platform is the facilitation of interaction between disciplines through the funding of various coordinated research projects, organization of common activities, and an adapted organization of the working environment. The platform was initiated with the simultaneous launch of $18 \mathrm{PhD}$ projects organized around five key innovation themes, looking at various aspects of the agro-ecosystem or developing new tools and technologies to apply in agriculture. The research facilities are open to all to enable international scientific collaboration. After three years of work, the actors within the platform produced a collection of review articles in order to structure the state-of-the-art on their five key innovation themes. This is the core of the present special issue, in which the following topics are considered.

The development of agroecology. Next to the widespread industrial agricultural model in Western Europe, several alternative models have been proposed to increase the environmental, social, and economic sustainability of agriculture. Hatt et al. (2016) reviewed and discussed what the paradigm of agroecology suggests in that perspective, from farming practices and the food system to the method of carrying out agricultural research and education. The inclusion of wildflower strips is an application of such an agroecological practice. In the agricultural landscapes of Wallonia, Belgium, which have experienced drastic biological simplification, wildflower strips have emerged as a tool to increase species richness and re-create ecological interactions within and along crop fields. Despite the creation of such strips that have been encouraged through subsidies, they are still often negatively perceived by farmers. Indeed, no clear assessment of their potential advantages, such as pest control, is available. Using a systematic literature search, Uyttenbroeck et al. (2016) reviewed the pros and cons of wildflower strips for farmers and highlighted important knowledge gaps.

The evolution of soil and organic residue management. Safeguarding long-term soil health is a key issue in the development of sustainable production systems. Although research topics like the fate of organic matter and tillage types are no longer new in agronomy, the complexity of the interactions they involve and feedback between abiotic and biotic parameters along with a lack of systematic and standardized experiments call for new approaches to gain better insight. Crop residues can be used to enhance biological activity and to incorporate organic matter in the soil, as shown by Lemtiri et al. (2016). Crop residues can also affect soil physical properties, resulting in relevant effects on crop production. However, literature shows that the effects of residue management on crop production are not unequivocal; therefore, there is a strong need to develop standardized experiments taking into account environmental factors. This latter aspect was developed by Hiel et al. (2016). Besides the management of crop residues, another crucial aspect of long-term soil health is an assessment of fertility. In the work by Renneson et al. (2016), the indicators of phosphorus status in soils were reviewed and the importance of interpretation was highlighted.

The development of tools for smart farming. Besides the adaptation of production systems themselves, a better knowledge of the existing one, through use of specific technology and tools, can help farmers to optimize production at reduced economic and environmental costs. These challenges are often addressed in the field of precision agriculture or smart farming. Farmers increasingly make use of sensors to acquire information about crops and animals and improve the efficiency of inputs, such as nutrients, water, etc. For example, the existing sensors to monitor cattle jaw movements and grazing behavior were reviewed by Andriamandroso et al. (2016). Another challenge of precision agriculture is to reduce the drift of pesticides in the case of spraying. In their review, Ouled Taleb Salah et al. (2016) assessed the relevance of controlled droplet application systems. 
The replacement of synthetic chemical inputs by biobased compounds. Replacing synthetic agro-chemicals by bio-based compounds has great potential to improve the sustainability of agriculture. Bio-stimulants, through their positive effects on the rhizosphere and plant development, represent a promising alternative to chemical fertilizers. Considering pest control, elicitors are notably developed as an agricultural tool to enhance plant resistance to diseases. If such biobased compounds were to be increasingly used in the future, many questions would remain (e.g., concerning application techniques, efficiency measurements, and legal aspects). These current challenges are reviewed by Le Mire et al. (2016).

The use of new bio-based resources for human consumption. Agricultural biomass contains such a wide variety of molecules that some are poorly known and/or little exploited. Three review articles are presented in this special issue, dealing with different types of molecules and/or purposes. Hamaidia et al. (2016) described the potential of 2-propylpentanoic acid, an active compound coming from crude extracts of Valeriana officinalis. Well-known in traditional medicine, the use of this compound is now validated to improve cancer treatment due to its ability to modulate epigenetics. Sphingolipids, which are present in the plasma membranes of plants, are another example of compounds that are currently not exploited despite their interest for industrial applications. Their structures, extraction, purification methods, and potential applications were developed in the review by Miazek et al. (2016). Besides plants, insects should not be forgotten as a source of high value material. Paul et al. (2016) demonstrated the nutritional value of grasshoppers, an insect group particularly common in temperate regions.

\section{AgricultureIsLife: the way forward...}

These different topics are presently developed in multi-disciplinary research projects, all including $\mathrm{PhD}$ students. Of course, this brief presentation should not be seen as a static list of research topics but instead as a first round of exploration in a larger, dynamic process that will hopefully advance agricultural sciences and explore further innovation opportunities. Over time, all stakeholders should be increasingly involved in the platform's activities and in agricultural research in general, through open-lab approaches.

Indeed, transforming promising research topics into practical innovations that provide long-term supporting and regulating ecosystem services will not only require scientific advances that are policyrelevant and economically viable, it will also depend on the adoption by farmers and the acceptance by consumers. The future will determine whether, and to what extent, the topics developed in the following pages yield fruitful innovations that will change the way we produce in Western Europe.

\section{Bibliography}

Andriamandroso et al., 2016. A review on the use of sensors to monitor cattle jaw movements and behavior when grazing. Biotechnol. Agron. Soc. Environ., 20(S1), 273286.

Ball D.A., 1992. Weed seedbank response to tillage, herbicides, and crop rotation sequence. Weed Sci., 40(4), 654-659.

Conway G. \& Toenniessen G., 1999. Feeding the world in the twenty-first century. Nature, 402, C55-C58.

Costantini V. \& Monni S., 2008. Environment, human development and economic growth. Ecol. Econ., 64(4), 867-880.

Costanza R. et al., 1997. The value of the world's ecosystem services and natural capital. Nature, 387(6630), 253-260.

Curl E.A., 1963. Control of plant diseases by crop rotation. Bot. Rev., 29(4), 413-479.

Dirzo R. \& Raven P.H., 2003. Global state of biodiversity and loss. Annu. Rev. Environ. Resour., 28(1), 137-167.

Etzkowitz H., 2003. Innovation in innovation: The Triple Helix of university-industry-government relations. Soc. Sci. Inf., 42, 293-337.

Evenson R.E. \& Gollin D., 2003. Assessing the impact of the green revolution, 1960 to 2000 . Science, 300(5620), 758-762.

Fernández-Giménez M.E. \& Estaque F.F., 2012. Pyrenean pastoralists' ecological knowledge: Documentation and application to natural resource management and adaptation. Hum. Ecol., 40(2), 287-300.

Halkier B., 1999. Consequences of the politicization of consumption: The example of environmentally friendly consumption practices. J. Environ. Policy Plann., 1(1), 25-41.

Hall A., 2009. Challenges to strengthening agricultural innovation systems: Where do we go from here? In: Scoones I. \& Thomson J., eds. Farmer first revisited: innovation for agricultural research and development. Sussex, UK: Practical Action Publishing, 30-38.

Hamaidia M. et al., 2016. From Valeriana officinalis to cancer therapy: The success of a bio-sourced compound. Biotechnol. Agron. Soc. Environ., 20(S1), 314-320.

Hatt S. et al., 2016. Towards sustainable food systems: the concept of agroecology and how it questions current research practices. A review. Biotechnol. Agron. Soc. Environ., 20(S1), 215-224.

Hiel M.-P. et al., 2016. Crop residue management in arable cropping systems under temperate climate. Part 2: Soil physical properties and crop production. A review. Biotechnol. Agron. Soc. Environ., 20(S1), 245-256. 
Le Mire G. et al., 2016. Review: implementing plant biostimulants and biocontrol strategies in the agroecological management of cultivated ecosystems. Biotechnol. Agron. Soc. Environ., 20(S1), 299-313.

Lemtiri A. et al., 2016. Crop residue management in arable cropping systems under temperate climate. Part 1: Soil biological and chemical (phosphorus and nitrogen) properties. A review. Biotechnol. Agron. Soc. Environ., 20(S1), 236-244.

Leydesdorff L. \& Etzkowitz H., 1998. The Triple Helix as a model for innovation studies. Sci. Public Policy, 25(3), 195-203.

Lin B.B., 2011. Resilience in agriculture through crop diversification: Adaptive management for environmental change. Bioscience, 61(3), 183-193.

Marie M., 2007. Deux générations d'agriculteurs face aux transformations des paysages bocagers. Étude de cas en Normandie. Cah. Écon. Sociol. Rurales, 84-85, 192-214.

Miazek et al., 2016. Sphingolipids: promising lipid-class molecules with potential applications for industry. A review. Biotechnol. Agron. Soc. Environ., 20(S1), 321336.

Ouled Taleb Salah S. et al., 2016. Étude des potentialités des systèmes d'application contrôlée des gouttes (CDA) pour les traitements phytosanitaires en céréaliculture (synthèse bibliographique). Biotechnol. Agron. Soc. Environ., 20(S1), 287-298.

Paul A. et al., 2016. Grasshoppers as a food source? A review. Biotechnol. Agron. Soc. Environ., 20(S1), 337352.

Perring M.P. et al., 2012. The Ridgefield multiple ecosystem services experiment: Can restoration of former agricultural land achieve multiple outcomes? Agric. Ecosyst. Environ., 163, 14-27.

Renneson M., Barbieux S. \& Colinet G., 2016. Indicators of phosphorus status in soils: Significance and relevance for crop soils in southern Belgium. A review. Biotechnol. Agron. Soc. Environ., 20(S1), 257-272.

Sayer J. \& Cassman K.G., 2013. Agricultural innovation to protect the environment. Proc. Natl. Acad. Sci. U.S.A., 110(21), 8345-8348.

Stern D., Common M.S. \& Barbier E.B., 1996. Economic growth and environmental degradation: The environmental kuznets curve and sustainable development. World Dev., 24(7), 1151-1160.

Storkey J. et al., 2012. The impact of agricultural intensification and land-use change on the European arable flora. Proc. R. Soc. London, Ser. B, 279, 14211429.

Tilman D., 1999. Global environmental impacts of agricultural expansion: the need for sustainable and efficient practices. Proc. Natl. Acad. Sci. U.S.A., 96(11), 5995-6000.

Tilman D. et al., 2002. Agricultural sustainability and intensive production practices. Nature, 418(6898), 671677.

Uyttenbroeck R. et al., 2016. Pros and cons of flowers strips for farmers. A review. Biotechnol. Agron. Soc. Environ., 20(S1), 225-235.

van Grinsven H.J.M. et al., 2015. Potential of extensification of European agriculture for a more sustainable food system, focusing on nitrogen. Environ. Res. Lett., 10(2), 025002 .

van Zanden J.L., 1991. The first green revolution: the growth of production and productivity in European agriculture, 1870-1914. Econ. Hist. Rev., 44(2), 215.

Vitousek P.M. et al., 1997. Human domination of earth's ecosystems. Science, 277(5325), 494-499.

(34 ref.) 